\title{
Hispanismes
}

Revue de la Société des Hispanistes Français

\section{La transmisión intergeneracional del gallego}

Estrategias familiares de mantenimiento y convivencia

La transmission intergénérationnelle de la langue galicienne. Stratégies

familiales de maintien et de coexistence

The intergenerational transmission of the Galician language. Family strategies

of maintenance and coexistence

\section{Henrique Monteagudo, Anik Nandi y Xaquín Loredo}

\section{OpenEdition}

Journals

Edición electrónica

URL: https://journals.openedition.org/hispanismes/782

DOI: 10.4000/hispanismes.782

ISSN: 2270-0765

Editor

Société des Hispanistes Français

Referencia electrónica

Henrique Monteagudo, Anik Nandi y Xaquín Loredo, «La transmisión intergeneracional del gallego», Hispanismes [En línea], 16 | 2020, Publicado el 01 diciembre 2020, consultado el 31 agosto 2021. URL: http://journals.openedition.org/hispanismes/782 ; DOI: https://doi.org/10.4000/hispanismes.782

Este documento fue generado automáticamente el 31 agosto 2021.

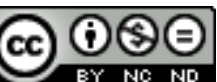

Les contenus de cette revue sont mis à disposition selon les termes de la Licence Creative Commons Attribution - Pas d'Utilisation Commerciale - Pas de Modification 4.0 International. 


\title{
La transmisión intergeneracional del gallego
}

\author{
Estrategias familiares de mantenimiento y convivencia \\ La transmission intergénérationnelle de la langue galicienne. Stratégies \\ familiales de maintien et de coexistence \\ The intergenerational transmission of the Galician language. Family strategies \\ of maintenance and coexistence
}

Henrique Monteagudo, Anik Nandi y Xaquín Loredo

\section{Introducción}

1 La UNESCO considera que una lengua está en peligro cuando «sus hablantes dejan de usarla, la usan en cada vez menos ámbitos de comunicación y dejan de transmitirla de generación en generación, es decir no hay nuevos hablantes, ni adultos ni niños» ${ }^{1}$. Este organismo enumeraba entre los principales indicadores para determinar la vitalidad de una lengua: 1) la transmisión intergeneracional, 2) el número absoluto de hablantes, 3) la proporción de hablantes sobre el conjunto de la población, 4) los cambios en los ámbitos de utilización del idioma, 5) los nuevos ámbitos y medios, y 6) la disponibilidad de materiales de enseñanza para aprender el idioma. Aplicando estos criterios al idioma gallego los resultados pueden resultar contradictorios, pues mientras la vitalidad demográfica de la lengua gallega es incuestionable, el panorama se ensombrece cuando se analizan otros indicadores importantes como la transmisión lingüística intergeneracional o las prácticas lingüísticas entre la gente más joven, especialmente aquella con un perfil urbano. Así, las proyecciones de futuro para el idioma gallego a medio y largo plazo son poco optimistas.

2 La situación actual de la lengua gallega subraya la urgencia de estudiar el papel de los diferentes agentes sociales implicados en los procesos de mantenimiento y recuperación lingüísticos en el contexto familiar. El trabajo que presentamos a continuación tiene como objetivo analizar la vitalidad de la lengua gallega. Con tal 
objetivo, partimos de los datos de transmisión lingüística intergeneracional y estudiamos el papel que juegan los diferentes perfiles sociolingüísticos familiares en los procesos de mantenimiento y recuperación del idioma minoritario con la finalidad de reconducir las políticas lingüísticas vigentes en Galicia, que se han revelado como poco efectivas $^{2}$. La primera parte del trabajo, utilizando un método cuantitativo, se centra en analizar la presencia, evolución y distribución espacial de los diferentes perfiles de transmisión lingüística familiar. La segunda parte del estudio, empleando un método cualitativo, recoge las diferentes estrategias lingüísticas utilizadas por cada tipología familiar.

3 Para ello, este trabajo se estructura en cuatro apartados. En el primero, se define el concepto de transmisión lingüística intergeneracional y su importancia para la situación actual del idioma gallego. En la segunda parte de la introducción se explican las estrategias familiares de la transmisión del gallego desde la perspectiva de la política lingüística. En el segundo apartado se expone la metodología utilizada en esta investigación. El tercero está centrado en la exposición de los resultados, concretados en los siguientes puntos: familias donde se mantiene la lengua familiar (3.1), familias caracterizadas por un proceso de sustitución de la lengua gallega por el castellano (3.2) $\mathrm{y}$, por último, familias donde se produce un proceso de recuperación de la lengua minoritaria (3.3). Por último, finalizamos este trabajo con una recapitulación sobre la importancia de la transmisión lingüística familiar y su transcendencia para la lengua gallega.

\section{1. La transmisión intergeneracional en Galicia}

Las principales encuestas demolingüísticas realizadas en Galicia durante estos últimos años retratan una sociedad bilingüe donde el $51,9 \%^{3}$ de la población habla habitualmente gallego, pero también reflejan algunas de las dificultades que la lengua gallega atraviesa derivadas de la histórica superposición del castellano. Así, el uso del gallego decrece como consecuencia de diversos factores, como la ruptura de la transmisión lingüística intergeneracional, la presión a favor del castellano en los medios urbanos, en las actividades profesionales y en el sistema educativo o la influencia de los medios de comunicación. Este contexto social hace de la convergencia hacia el castellano o incluso el cambio de lengua habitual a favor del idioma dominante por parte de gallegohablantes la opción más fácil. Por el contrario, los condicionamientos contextuales y las presiones ambientales son mucho menos propicias para las prácticas lingüísticas favorables hacia el gallego por parte de los castellanohablantes, por lo que exigen una motivación mucho mayor que las inversas.

5 La figura 1 presenta un panorama general de la situación sociolingüística gallega teniendo en cuenta uno de los factores de mayor transcendencia en la sociolingüística gallega, el factor geográfico. La población gallega se agrupa mayoritariamente sobre el conocido como "eje atlántico", especialmente en las áreas urbanas de A Coruña y Vigo, donde se concentra el tejido socioeconómico de Galicia; y es precisamente en este eje donde el número de castellanohablantes supera el de gallegohablantes, con la excepción de la comarca de Santiago de Compostela. La situación en las provincias interiores y costeras de Galicia es la inversa: el número de hablantes habituales de gallego supera el de hablantes de castellano, a excepción de la comarca de Ourense; sin 
embargo, el número de habitantes de estas es mucho menor que el de las comarcas que conforman el eje atlántico.

Figura 1. Frecuencias de gallegohablantes y castellanohablantes por comarcas y número de habitantes ${ }^{4}$.

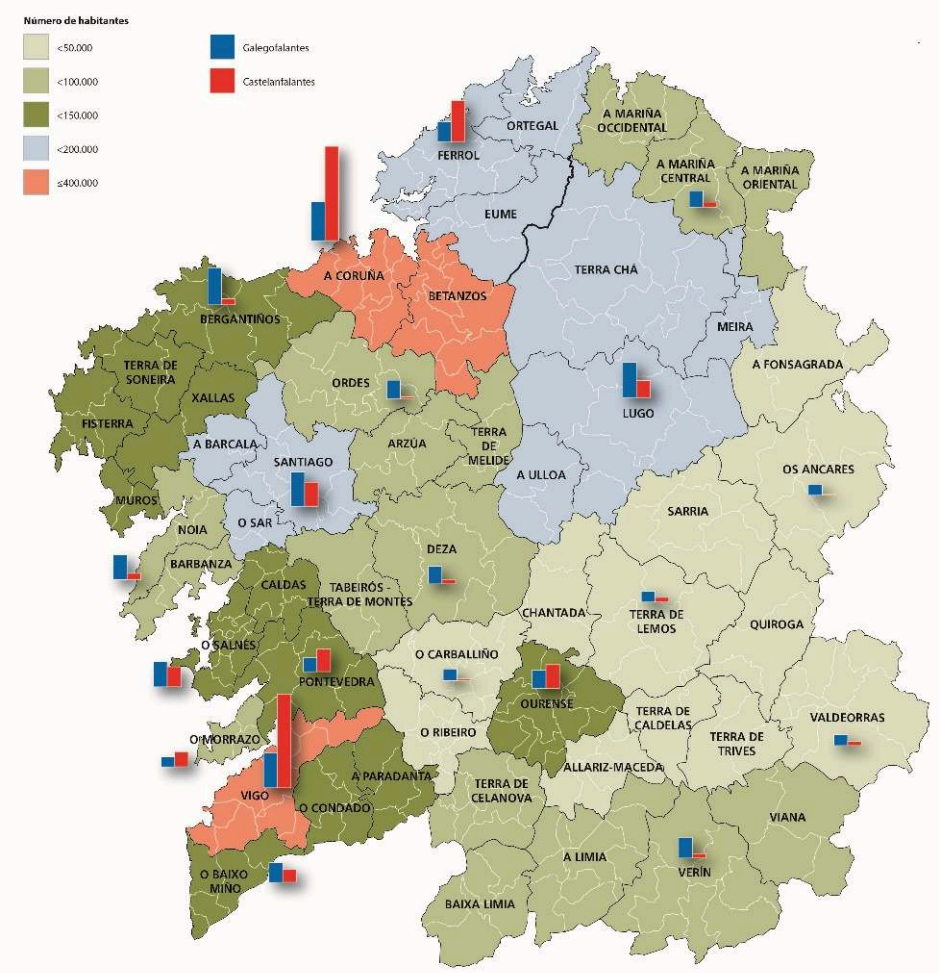

6 La sustitución progresiva del gallego por el castellano durante la segunda mitad del siglo pasado se relacionó con factores como la masiva emigración de la población rural gallegohablante, los procesos de urbanización e industrialización, el acceso a la educación y la extensión de los medios de comunicación audiovisuales, entre otros ${ }^{5}$. Muchas familias procedentes del medio rural, plegándose a las exigencias para la integración y el ascenso social en el medio urbano, fueron incorporando el castellano a su repertorio comunicativo, tanto en los ámbitos formales como en los informales, incluida la transmisión familiar. Por el contrario, segmentos castellanizados de la pequeña burguesía urbana cultivada mantuvieron o recuperaron el uso del gallego como una forma de reivindicación de su identidad étnica y política.

7 Los procesos de reproducción lingüística en el contexto familiar tuvieron una importancia decisiva para que la lengua gallega llegase al siglo XXI con la elevada vitalidad demográfica que, de momento, conserva. Sin embargo, los procesos de desgalleguización tuvieron y tienen una importancia notable, que supera en número a los de regalleguización que, aunque menos frecuentes, poseen gran relevancia cualitativa y marcado carácter ideológico ${ }^{6}$. Es así que la situación sociolingüística gallega actual se caracteriza por la presencia de dinámicas familiares interconectadas entre las que destaca la convivencia de procesos de mantenimiento de la transmisión intergeneracional en el contexto familiar (i.e. gallego, castellano) junto a procesos de ruptura de esta transmisión (i.e. desgalleguización, regalleguización). 


\subsection{Estrategias familiares para la transmisión del gallego}

8 Una parte de este trabajo está orientado al estudio de las estrategias familiares de la transmisión del gallego desde la perspectiva de la política lingüística (PL, a partir de ahora), concretamente, al estudio de la política lingüística familiar (PLF, a partir de ahora) analizando aquellos factores más relevantes para comprender las prácticas lingüísticas que tienen lugar en las familias gallegas integradas en los diferentes perfiles sociolingüísticos. En definitiva, esta parte quiere comprender qué tipo de decisiones y/o elecciones sobre la lengua toman las familias mantenedoras, frente a las familias caracterizadas por procesos de desgalleguización o regalleguización.

9 Partiendo del papel fundamental de la familia en el aprendizaje de la/s lengua/s, especialmente las iniciales, no hay que perder de vista los cambios sufridos por esta institución durante estos últimos años que han podido modificar su «papel» en los procesos de reproducción lingüística generacional, provocando que otras instituciones fueran ganando más importancia en los procesos de socialización primaria. Con todo, la familia sigue siendo la unidad social vital para la adquisición y el aprendizaje de las lenguas ${ }^{7}$.

En los procesos de transmisión lingüística intergeneracional influyen factores macrosociales (sociolingüísticos, socioeconómicos, socioculturales, urbanísticos) a través de diferentes instituciones sociales (familia, sistema educativo, comunidad y medios de comunicación entre otros) ${ }^{8}$. Cuando las diferentes variables involucradas en la promoción de la transmisión de la lengua minoritaria no se acaban de sincronizar, puede suceder que la familia juegue un papel activo en la reproducción lingüística, pero que la acción de otros actores eventualmente cambie la distribución funcional de las lenguas en ese contexto9.

11 Louis-Jean Calvet describe la familia como un "campo de batalla» ${ }^{10}$; con esta metáfora da cuenta del conflicto que puede implicar la planificación y gestión lingüística en hogares bilingües, donde la elección de lengua está en proceso de continua negociación ${ }^{11}$. Aunque la investigación sobre familias bilingües ya es un campo bien establecido, la PLF comenzó como un campo de estudio independiente en la última década, tomando en cuenta las decisiones explícitas y/o implícitas que los miembros adultos de la familia toman sobre el aprendizaje y el uso de la(s) lengua(s) por parte de los niños en el ámbito doméstico ${ }^{12}$.

12 La PL, bien proceda del gobierno o bien se dé dentro de la familia, contiene tres elementos básicos: ideologías lingüísticas (basadas en las creencias de la comunidad), gestión lingüística (planificación en todos los niveles) y prácticas de la lengua ${ }^{13}$. Las prácticas lingüísticas están relacionadas con la ecología del lenguaje ${ }^{14}$; es decir, se refieren a los comportamientos lingüísticos sistemáticos y esperados que constituyen el uso del idioma en diferentes contextos y para fines específicos. A su vez, las ideologías lingüísticas se manifiestan en las prácticas lingüísticas. Por ejemplo, en contextos familiares, los padres transmiten su ideología lingüística a los hijos mediante las opciones lingüísticas realizadas en las interacciones en una sociedad bilingüe. Es decir, el mero hecho de utilizar una lengua y no otra en las interacciones con sus hijos puede reflejar las ideologías que los padres tienen respecto al valor de las lenguas presentes en el entorno familiar y social ${ }^{15}$. 
13 La gestión lingüística en PLF, por su parte, se refiere a las decisiones conscientes y explícitas de los padres y otros miembros adultos de la familia para mantener el control del comportamiento lingüístico de los niños en un contexto dado. Las expectativas de los padres respecto al desarrollo lingüístico de los hijos constituyen uno de los aspectos más significativos de la PLF, en la medida en que son estas expectativas las que mejor señalan los objetivos de la PL del hogar ${ }^{16}$. Por otra parte, existen otros elementos como el idioma de los progenitores, el conocimiento del bilingüismo social, las experiencias personales con el idioma minoritario, el ambiente de alfabetización en el hogar, las relaciones sociales de los padres fuera de la familia y el acceso familiar a diferentes tipos de capitales, entre otros, que también determinan la planificación del idioma dentro del contexto familiar. Otro elemento importante de la gestión lingüística es la intervención de los padres, quienes incorporan una serie de actividades de alfabetización formales e informales, como leer libros juntos, apoyar las tareas escolares o buscar ayuda profesional externa a través de las clases particulares. Sin embargo, la distinción entre gestión y práctica lingüística dentro de la familia a veces es confusa, porque los padres pueden llegar a controlar o intervenir en el uso del idioma de sus hijos a través de correcciones de errores.

\section{Método}

14 El campo de estudio de la sociolingüística gallega se ha visto inmerso estos últimos años en una discusión metodológica, pues si la metodología de encuestas fue la más frecuente durante el pasado siglo, las críticas a su validez y fiabilidad de aplicación a la disciplina han dado paso, durante los primeros años del siglo XXI, a una metodología de corte cualitativo centrada en grupos de discusión y, posteriormente, entrevistas en profundidad; en esta recién iniciada segunda década del siglo XXI el método etnográfico está comenzando a ser utilizado en la investigación sociolingüística en Galicia. Este trabajo quiere iniciar una línea de investigación donde prime la colaboración entre investigadores que trabajen desde la óptica etnográfica y aquellos investigadores que lo hagan desde un enfoque demolingüístico, es decir, este estudio consta de dos partes en las que se utilizan dos metodologías diferenciadas: a) Parte I, metodología cuantitativa; b) Parte II, metodología de corte cualitativo.

\subsection{Estudio cuantitativo}

Para este trabajo se utilizaron los resultados extraídos de la «Enquisa estrutural a fogares» del Instituto Galego de Estatística (a partir de ahora: IGE), aplicada quinquenalmente desde el año 2003 y que incluye un módulo específico denominado «Módulo de conocimiento y uso del gallego». La base de datos utilizada es del año $2018^{17}$, de donde se seleccionó a los entrevistados que cumplían el requisito de personas con hijos.

Para construir los perfiles familiares que son objeto de estudio en este trabajo se tuvieron en cuenta los siguientes criterios: a) el mantenimiento de la lengua familiar (i.e. sí, no), b) el idioma (i.e. gallego, castellano) y la generación (i.e. abuelos/as, progenitores/as e hijos/as del entrevistado). Teniendo en cuenta esta serie de variables que giran alrededor de la transmisión lingüística intergeneracional obtenemos dos perfiles de familias: aquellas que reproducen la lengua familiar durante varias 
generaciones (i.e. mantenedoras/reproductoras) y aquellas que no (i.e. no mantenedoras); posteriormente estas agrupaciones se subdividen obteniendo un total de seis grupos (ver Tabla 1).

En primer lugar, tenemos las familias caracterizadas por una PLF de mantenimiento/ reproducción del idioma gallego (GA) y, por otro lado, aquellas que mantienen el castellano (CAST). Para que una familia llegue a formar parte de alguno de estos grupos, el proceso de reproducción de la lengua familiar tuvo que asentarse como mínimo a lo largo de tres o más generaciones (i.e. abuelos a progenitores, progenitores a entrevistado y/o entrevistado a descendientes). Por otro lado, se encuentran los núcleos familiares que están inmersos en un proceso de cambio lingüístico intergeneracional y que puede consistir tanto en la sustitución del gallego por el castellano (DESGA1, DESGA2), como en la sustitución del castellano por el gallego (REGA1, REGA2). Dentro de estos procesos de cambio debe distinguirse entre los asentados (DESGA2, REGA2), en los cuales el cambio se extiende a dos generaciones (progenitores a entrevistado y entrevistado a descendientes) y los no asentados (DESGA1, REGA1), aquellos en los que el cambio intergeneracional se produjo durante esta generación (entrevistado a descendientes).

Tabla 1. Perfiles familiares según sus políticas lingüísticas de mantenimiento y de cambio intergeneracional

\begin{tabular}{|c|c|c|c|}
\hline Política lingüística familiar & \multicolumn{2}{|l|}{ Denominación } & Acrónimo \\
\hline \multirow{2}{*}{ Familias mantenedoras } & Gallegohablantes & & GA \\
\hline & Castellanohablantes & & CAST \\
\hline \multirow{4}{*}{$\begin{array}{l}\text { Familias no mantenedoras (familias en } \\
\text { proceso de cambio) }\end{array}$} & \multirow{2}{*}{ Desgalleguizadoras } & $\begin{array}{l}1^{\mathrm{a}} \quad \text { generación (no } \\
\text { asentado) }\end{array}$ & DESGA1 \\
\hline & & $\begin{array}{l}2^{\text {a }} \text { generación } \\
\text { (asentado) }\end{array}$ & DESGA2 \\
\hline & \multirow{2}{*}{ Regalleguizadoras } & $\begin{array}{l}1^{\text {a }} \text { generación (no } \\
\text { asentado) }\end{array}$ & REGA1 \\
\hline & & $\begin{array}{l}2^{\mathrm{a}} \text { generación } \\
\text { (asentado) }\end{array}$ & REGA2 \\
\hline
\end{tabular}

Como ya se indicó, este trabajo utiliza la «Enquisa estrutural a fogares», antes denominada «Encuesta de condiciones de vida de las familias», actividad estadística que realiza el IGE desde 1999. Esta encuesta, que se dirige a los hogares gallegos con la finalidad de obtener información sobre sus características socioeconómicas, consta de dos módulos: el primero es de carácter general y se repite anualmente, mientras que el segundo, más específico, está conformado por bloques temáticos de variables que muestran una evolución más lenta, por lo que no necesitan una recolección anual de datos. El «Módulo de coñecemento e uso do galego» se encontraría en este segundo módulo y se repitió, con modificaciones, quinquenalmente durante los años 2003, 2008, 
2014 y 2018. La «Enquisa estrutural a fogares» aplicada en 2018 incorporaba una parte específica denominada «Módulos de novas tecnoloxías e coñecemento e uso do galego».

\subsection{Estudio cualitativo}

19 Como ya se ha explicado antes, este trabajo utiliza una metodología mixta basada en la combinación entre métodos cuantitativos y cualitativos. Esta segunda parte del trabajo está centrada en la utilización de herramientas etnográficas dentro de la metodología cualitativa. La PL es un fenómeno complejo en el que diferentes actores actúan en distintas escalas. Para una mejor comprensión de estos niveles y sus actores, Ricento y Hornberger ${ }^{18}$ metafóricamente compararon el proceso de la PL con una cebolla donde las diferentes capas representan diferentes escalas de este proceso. Así, mientras que las capas externas representan macrofactores del nivel gubernamental y la comunidad de habla, las capas internas se refieren al nivel escolar, a prácticas lingüísticas dentro del aula, a la familia o al comportamiento lingüístico de un individuo en el ámbito doméstico, entre otros. Dichos investigadores optaron por los métodos etnográficos para una mejor comprensión de estos factores y sus influencias en los diferentes actores. La etnografía se refiere al estudio directo de personas y/o grupos durante un cierto período, utilizando principalmente la observación participante y las entrevistas para descubrir su comportamiento social ${ }^{19}$. En este sentido, esta técnica podría ser uno de los métodos más apropiados para descubrir las motivaciones detrás de la sustitución lingüística, las ideologías que impulsan estos cambios $\mathrm{y}$, sobre todo, las prácticas lingüísticas de los individuos en distintos contextos de socialización.

Partiendo de las herramientas etnográficas, este trabajo se apoya en notas de campo y observación y en entrevistas semiestructuradas realizadas a seis progenitores del contexto periurbano y urbano de Santiago de Compostela ${ }^{20}$. Para este estudio se seleccionaron progenitores que pasaron por el sistema educativo de Galicia a partir del 1975 y vivieron las primeras PLs autonómicas, es decir personas con edades comprendidas entre los 35 y 55 años. No queremos dejar de señalar que todos los participantes son funcionarios de la Xunta de Galicia, por lo tanto, pertenecientes a un sector económicamente acomodado y representan, en gran parte, la clase media, media-alta gallega. La tabla 2 proporciona una visión general de las familias que vamos a presentar como estudios de caso y su relación con los perfiles explicados en la tabla 1. Se utilizan nombres ficticios para mantener el anonimato de los participantes:

Tabla 2. Una visión general de los progenitores entrevistados

\begin{tabular}{|c|c|c|c|}
\hline Familias entrevistadas & Edad & Menores y centros escolares & Profesiones \\
\hline $\begin{array}{l}\text { 1. Familia Quintana-Lago } \\
\text { Perfil: Familia mantenedoras, } \\
\text { gallegohablantes. } \\
\text { Martín } \\
\text { Claudia } \\
\text { Lengua dominante: gallego }\end{array}$ & $\begin{array}{l}55 \\
52\end{array}$ & $\begin{array}{l}\text { Tienen cuatro hijas y tres de ellas } \\
\text { estudian en la escuela primaria de } \\
\text { Bertamiráns. }\end{array}$ & $\begin{array}{l}\text { Profesor } \\
\text { (colegio) } \\
\text { Bibliotecaria }\end{array}$ \\
\hline
\end{tabular}




\begin{tabular}{|c|c|c|c|}
\hline $\begin{array}{l}\text { 2. Familia Pérez-Gómez } \\
\text { Perfil: Familia no mantenedora, } \\
\text { desgalleguizada } 1^{\text {a }} \text { generación. } \\
\text { Javier } \\
\text { Julia } \\
\text { Lengua dominante: castellano }\end{array}$ & 36 & $\begin{array}{l}\text { Tienen una hija y un hijo que estudian } \\
\text { en la escuela primaria de Bertamiráns. }\end{array}$ & $\begin{array}{l}\text { Veterinario } \\
\text { Veterinaria }\end{array}$ \\
\hline $\begin{array}{l}\text { 3. Familia Romero-Mouzo } \\
\text { Perfil: Familia no mantenedora, } \\
\text { regalleguizada, } 1^{\mathrm{a}} \text { generación. } \\
\text { Samuel } \\
\text { Raquel } \\
\text { Lengua dominante: gallego }\end{array}$ & 40 & $\begin{array}{l}\text { Tienen dos hijas que estudian en } \\
\text { Semente en Santiago. }\end{array}$ & $\begin{array}{l}\text { Profesor } \\
\text { (Instituto) } \\
\text { Profesora } \\
\text { (colegio) }\end{array}$ \\
\hline
\end{tabular}

21 Para analizar los datos, se aplicó un análisis temático ${ }^{21}$, que permite obtener una perspectiva más amplia sobre las múltiples experiencias personales, a partir de las narraciones en que se plasma el discurso sobre las PLs implícitas del nivel micro. Las observaciones e ideas iniciales se fueron anotando desde la fase de entrevistas. Una vez terminada la transcripción, el material se revisó varias veces para generar los códigos preliminares que planteaban las preguntas principales de esta investigación. Después, las primeras categorías fueron preparándose en base a estos códigos, que se referían al desarrollo de la política lingüística familiar. Finalmente, varias categorías interrelacionadas dieron forma a los temas que respondían a los ejes de esta investigación. Es importante anotar que los temas que no contaban con suficientes datos para apoyarlos fueron excluidos del análisis para mantener la claridad del enfoque de la investigación.

\section{Los perfiles sociolingüísticos familiares}

A continuación, presentamos los resultados de las diferentes agrupaciones según sus PL de reproducción o cambio del idioma familiar. Para la distinción entre los diferentes perfiles familiares se toma como referencia la transmisión o ruptura intergeneracional del idioma de la familia. La elaboración de los perfiles lingüísticos familiares en Galicia es una línea investigación del actual equipo de trabajo ${ }^{22}$, aunque se han realizado algunas modificaciones sobre las categorías presentadas en relación con publicaciones anteriores ampliando el número de generaciones que se tuvieron en cuenta para el análisis y se han descartado las alternativas intermedias para fomentar el carácter divulgativo de la publicación.

El perfil sociolingüístico familiar más numeroso en Galicia son aquellas familias que siguen una PLF de reproducción del idioma gallego (53,6\%), familias caracterizadas por seguir una línea de mantenimiento del idioma gallego en el núcleo familiar durante generaciones (GA), es decir, los datos retratan una situación donde el idioma minorizado en Galicia es más transmitido que la lengua dominante en el núcleo familiar, el castellano, que alcanza una presencia importante (CAST: 22\%), por lo que a priori, los datos retratan una situación sociolingüística propicia para el idioma propio. 
No obstante, esta valoración cambia cuando se incluyen en el análisis factores como la cronología o la distribución espacial de las familias. Las familias reproductoras/ mantenedoras del castellano (CAST) tienen una presencia importante (22\%), aunque bastante inferior al de las familias GA, ya que non llegan a suponer ni la mitad. Es decir, las familias que reproducen el castellano en su núcleo familiar y que perdieron los referentes familiares en gallego es un perfil importante pero no tan numeroso como el GA. No obstante, es un perfil que está en continuo crecimiento dado el gran poder social y simbólico del castellano (Figura 2).

Las familias GA que están en proceso de cambio, en concreto, aquellas que no transmiten a sus descendientes la lengua recibida por sus progenitores, es decir que están en procesos de desgalleguización (i.e. DESGA1, DESGA2) suponen un 22\% del total da población. Un $15 \%$ está inmerso en este proceso que se está produciendo durante esta generación (i.e. DESGA1), mientras que un 7\% ya provenía de la generación anterior (i.e. DESGA2).

Las cifras relacionadas con los núcleos familiares con PLF caracterizadas por un proceso de recuperación del idioma gallego son relativamente bajas (i.e. REGA1, REGA2), de hecho, estos dos perfiles sumarían un total de un $2,4 \%$. No obstante, estos perfiles tienen una gran importancia simbólica para los procesos de recuperación de las lenguas minoritarias en contextos no favorables.

Figura 2. Distribución porcentual de los perfiles lingüísticos familiares en Galicia.

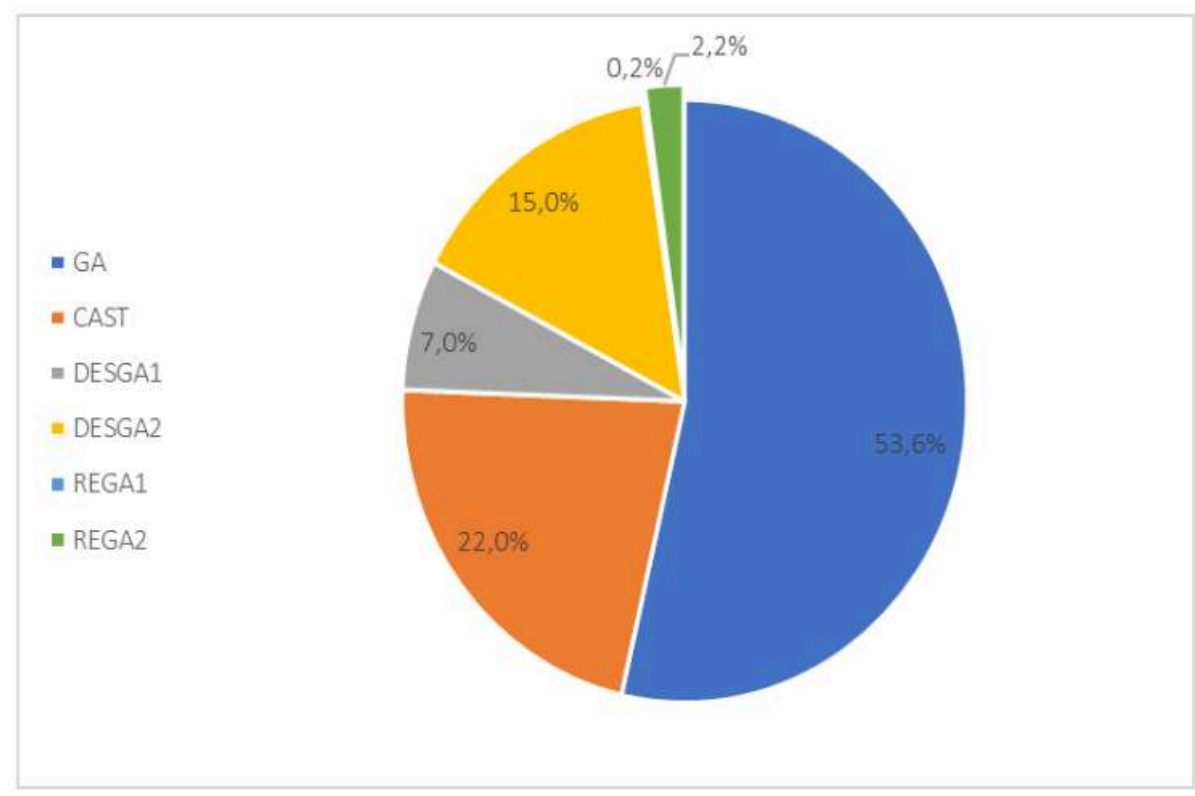

\subsection{El mantenimiento de la lengua familiar}

En Galicia, las familias se caracterizan por un perfil sociolingüístico donde prima el mantenimiento de la lengua familiar. El apartado anterior indicaba al GA como el perfil lingüístico familiar más numeroso $(53,6 \%)$ seguido a bastante distancia por el CAST, núcleos familiares reproductores del castellano (22\%). Sin embargo, sumando a las familias caracterizadas por la retención del castellano (CAST) a aquellas que están en proceso de sustitución del gallego por el castellano (i.e. DESGA1, DESGA2), entre esta 
generación y la siguiente la mitad de la población gallega perdería sus referentes en lengua gallega y el perfil CAST pasaría, lentamente pero inevitablemente, a ser el perfil más numeroso si las PL aplicadas no consiguieran modificar esa dinámica.

El análisis temporal de los perfiles sociolingüísticos familiares caracterizados por la retención lingüística (GA, CAST) revela las dinámicas internas del sistema de convivencia de las lenguas en el ámbito familiar gallego. Así, como acabamos de ver, los datos generales señalan al perfil GA como mayoritario, mientras que desde una perspectiva evolutiva este perfil va lentamente perdiendo presencia con el transcurso de los años, partiendo de una posición mayoritaria entre los nacidos durante la primera mitad del siglo XX, pero descendiendo a cifras inferiores al 50\% durante la segunda mitad (Figura 3). En contraposición con la evolución negativa del perfil familiar de reproducción del idioma gallego, el CAST ha ido paulatinamente adquiriendo importancia, pues de tratarse de un perfil familiar casi testimonial a mediados del siglo pasado (nacidos antes de 1944: 11,5\%), actualmente representa la mitad de la población con hijos nacidos a finales del siglo pasado. Estos dos perfiles, complementarios con procesos intermedios de cambio, retratarían una situación de ruptura de la transmisión del gallego en el contexto familiar provocado por un proceso de sustitución de la lengua minoritaria por la mayoritaria en las prácticas lingüísticas familiares, fundamentales para la supervivencia del idioma. Además, estos resultados nos aproximan a los diversos factores que desde mediados del siglo pasado afectan negativamente a las prácticas lingüísticas familiares (por ej.: socioeconómicos, movimientos migratorios, avances tecnológicos, políticas lingüísticas).

Complementariamente a la situación descrita, incorporamos un segundo factor a la ecuación: la distribución territorial, que retrata de una forma clara cómo las familias que llevan reproduciendo el idioma gallego durante generaciones se ubican fundamentalmente en contextos rurales (-10.000 habitantes), tratándose de un perfil minoritario en contextos urbanos (más de 50.000 habitantes). Por el contrario, los perfiles familiares castellanohablantes son numerosos en los contextos urbanos; el $40 \%$ de las familias residentes en las ciudades gallegas ya han perdido sus referencias familiares con el idioma propio de Galicia (Figura 4). 
FIgURA 3. EVOLUCIÓN CRONOLÓgICA DE LOS PERfiLeS LINgÜíSTICOS FAMILIARES TRASMISORES DEL gALLEO DURANTE gENERACIONES (GA) Y TRASMISORES DEL CASTELLANO DURANTE gENERACIONES (CA).

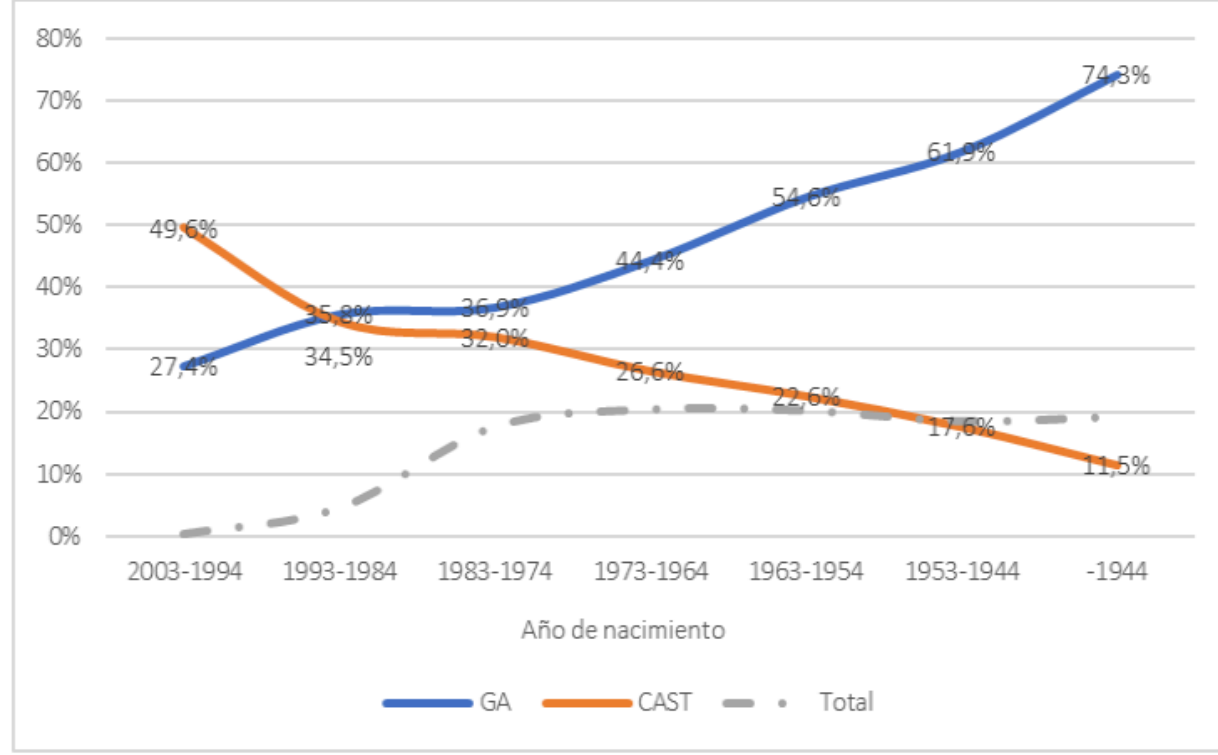

FIgURA 4. DISTRIBUCIÓN POR TAMAÑo DEL HÁBITAT dE RESIDENCIA DE LOS PERfiles LINgÜísticos FAMILIARES TRASMISORES DEL GALLEO DURANTE GENERACIONES (GA) Y TRASMISORES DEL CASTELLANO DURANTE gENERACIONES (CA).

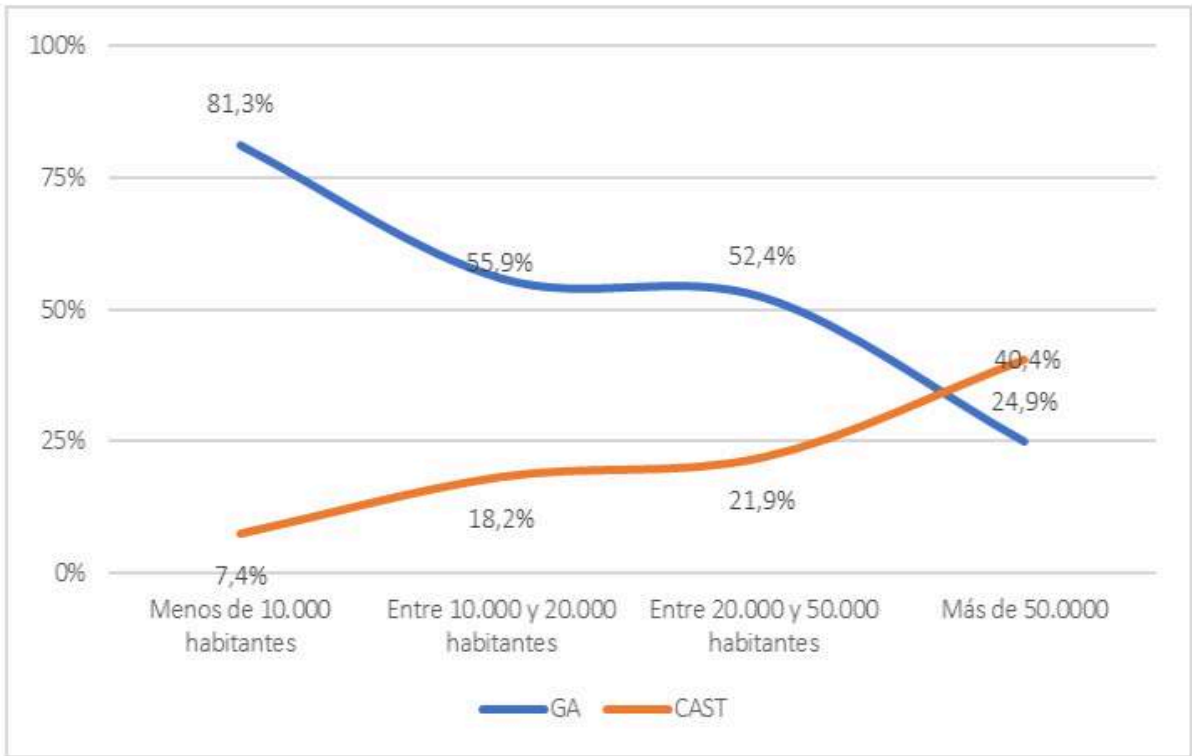

El abordaje etnográfico completa nuestro análisis de las familias reproductoras del idioma gallego visibilizando las estrategias familiares que se ven obligadas a adoptar ante la presión del idioma dominante. El estudio de caso ejemplifica cómo se inicia un futuro proceso de ruptura de la transmisión intergeneracional en un contexto no favorable hacia la lengua minoritaria, un contexto urbano. Se trata de una familia de 
clase media con progenitores nacidos en la década de los sesenta, la familia QuintanaLago (Tabla 1). Los progenitores, Martín y Claudia, pertenecen a familias que llevan utilizando el idioma gallego durante generaciones en todos los contextos. Tienen cuatro hijas, de diferentes edades, tres de ellas actualmente estudian en un Centro de Educación Infantil y Primaria (CEIP) en el periurbano de Santiago de Compostela. Las entrevistas individuales con los padres y las notas de observación confirman que los progenitores tienen una PLF favorable al gallego. Sin embargo, aunque los progenitores y la hija mayor siempre interaccionan en gallego, las otras tres hijas utilizan habitualmente el castellano en todos los contextos de socialización. Claudia subrayó durante su entrevista las diferentes estrategias aplicadas con sus hijas para que hablaran gallego (por ej., solo usar este idioma en el contexto familiar o llevar a sus tres hijas a un programa de inmersión lingüística):

Entón pasamos as nosas dúas fillas alí, á liña de galego, aunque nosotros, non era necesario porque nosotros xa falábamos en galego, e elas falaban galego, pero resulta que cambiaron de idioma. Cambiaron de idioma, incluso coa liña estando na liña de galego. [En gallego, idioma original de la entrevista].

'Entonces, enviamos a nuestras tres hijas a la línea del gallego en el colegio, aunque no era necesario porque ya hablábamos gallego en casa, y ellas también, pero resulta que cambiaron de idioma cuando comenzaron el colegio. Cambiaron de idioma, incluso estando en la línea del gallego'. [traducción propia].

En el contexto sociolingüístico de Galicia, el castellano es el idioma predominante en los contextos urbanos/periurbanos. Las escuelas públicas en estas zonas también están altamente castellanizadas porque la mayoría de los escolares tienen establecido el español como la lengua para sus relaciones informales ${ }^{23}$. En consecuencia, aunque algunas familias con padres gallegohablantes logran que sus descendientes hablen durante los primeros años de la infancia, existen estudios que indican que la sustitución del gallego por el castellano comienza a introducirse en los niveles educativos de Infantil y Primaria por procesos de imitación, continuado en cuanto los menores llegan a la preadolescencia y se dan cuenta de que hablan un idioma diferente que sus compañeros de aula y/o amigos y desean integrarse con ellos. Por lo tanto, la supuesta hipótesis de estos padres sobre el hogar o los programas de inmersión lingüística como un espacio seguro para fomentar el uso del gallego y/o su revitalización puede fallar a medida que los niños desarrollan su propia agencia. Esta situación se debe a que el castellano posee un mayor capital social y poder simbólico que el gallego y, como lengua predominante en el exterior (fuera de la casa y el aula), a través de su control hegemónico, está creando discrepancias y desconformidades en la práctica lingüística dentro del hogar.

\subsection{Los procesos de desgalleguización}

31 Los perfiles sociolingüísticos caracterizados por procesos de desgalleguización están asociados a procesos de ruptura de la transmisión lingüística intergeneracional del idioma gallego en el contexto familiar, tanto en la generación actual (DESGA2, el idioma recibido de los progenitores es distinto que el transmitido a los descendientes) como durante la generación anterior (DESGA1, la lengua que los abuelos transmitieron a los progenitores es distinta de la que los progenitores transmitieron a la persona entrevistada). Los resultados señalan la existencia de un claro proceso de desgalleguización que se mantiene con el transcurso de los años, dado el gran poder de 
atracción del idioma español, aspecto relacionado con factores diversos como prestigio social, políticas lingüísticas, etc.

En cuanto a la presencia del perfil DESGA2 por cohortes de edad, los datos oscilan entre los $11,8 \%$ para los nacidos antes de 1944 hasta el 14\% para aquellos nacidos entre 1984 y 1993; es decir, el proceso de desgalleguización se mantiene a lo largo del tiempo con cifras próximas al $15 \%{ }^{24}$. Complementariamente se observa el crecimiento de este proceso de ruptura de la transmisión lingüística, que de ser prácticamente inexistente en los progenitores nacidos a mediados del siglo XX, llega a alcanzar cifras importantes a finales de este (Figura 5). Estos datos dibujan el proceso de sustitución del gallego por el castellano en Galicia y cómo se va asentando con el paso de una generación a la siguiente.

Figura 5. Evolución de los perfiles lingüísticos de desgalleguización asentada (DESGA1) y desgalleguización no asentada (DESGA2) por cohortes de edad.

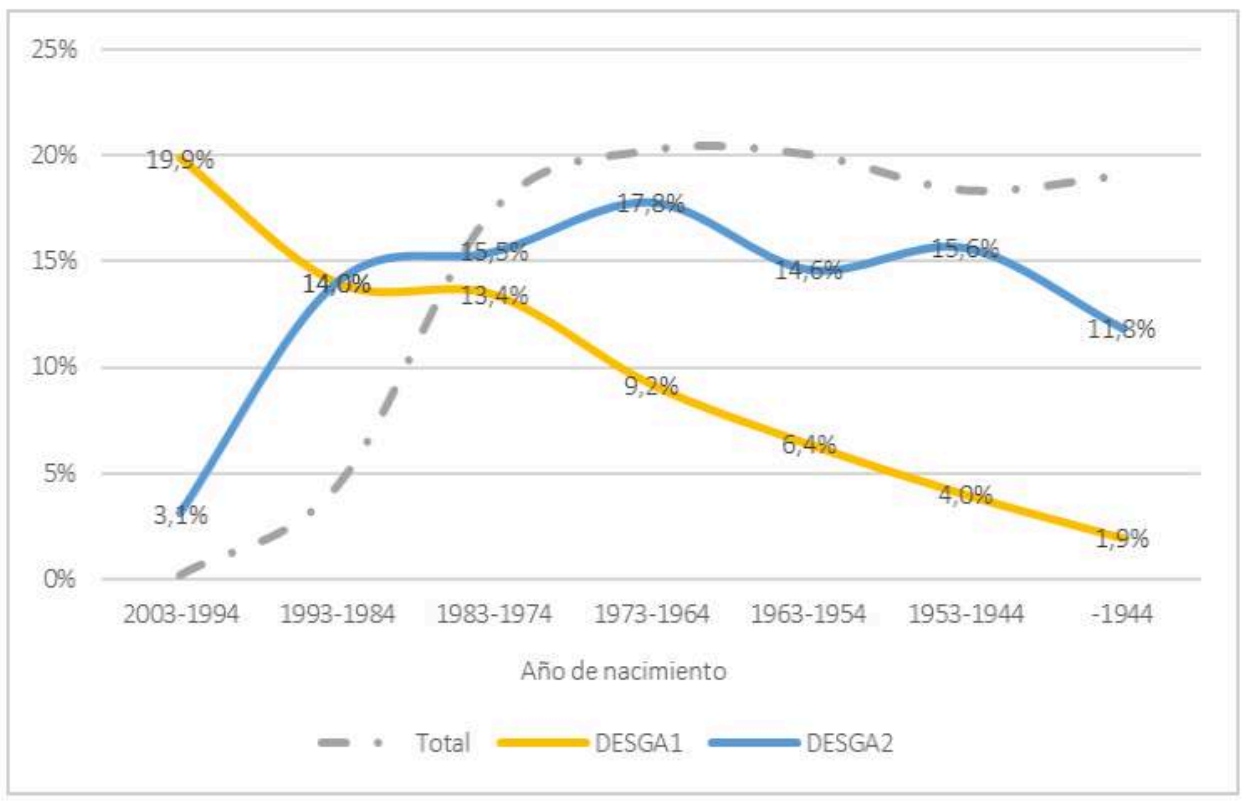

Del análisis de la distribución de los perfiles de desgalleguización según la variable de tamaño del ayuntamiento de residencia (Figura 5) se pueden extraer varias conclusiones. En primer lugar, las cifras referentes a las familias DESGA1 indican que los procesos de desgalleguización estuvieron centrados en los espacios urbanos. Además, estos datos evidencian que los procesos de desgalleguización en la generación actual (DESGA2) han ampliado su radio de acción e incluyen también centros periurbanos y vilas $^{25}$ (Figura 6). 
Figura 6. Evolución de los perfiles lingüísticos de desgalleguización asentada (DESGA1) y desgalleguización no asentada (DESGA2) por tamaño del hábitat de residencia.

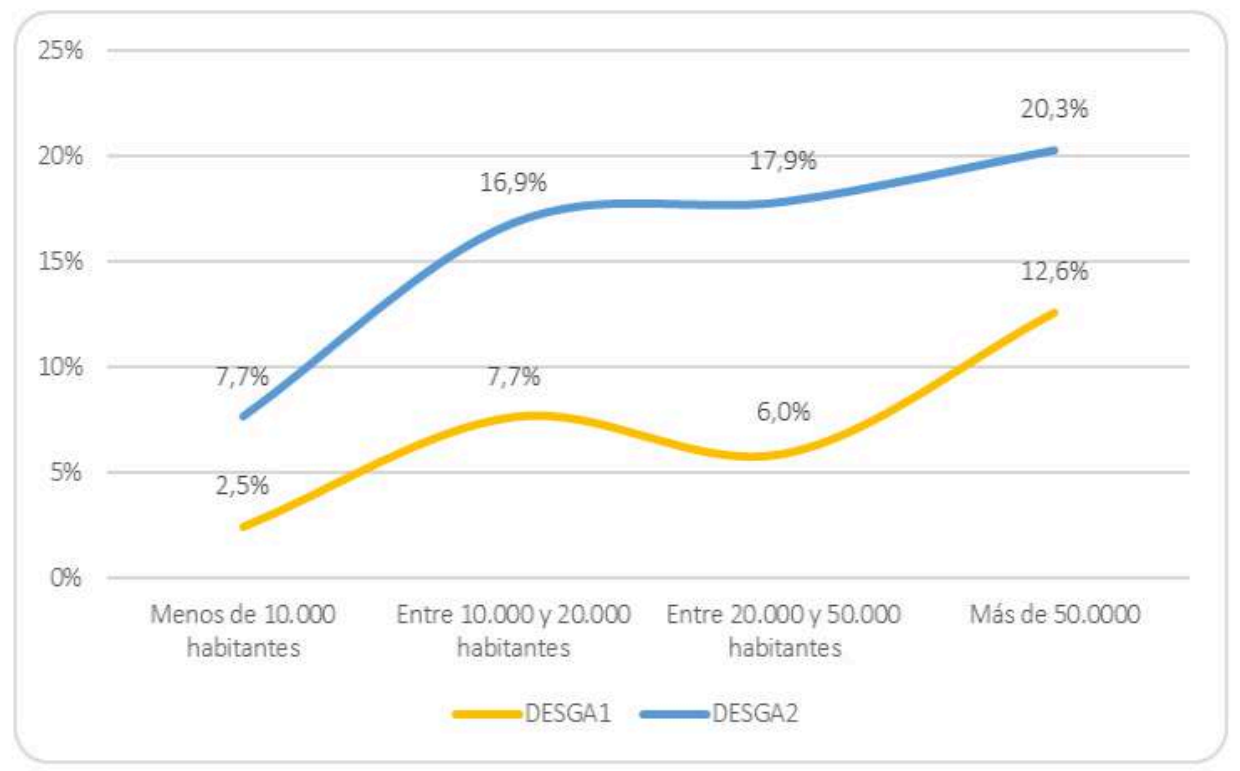

Para analizar los perfiles de desgalleguización escogimos analizar las estrategias lingüísticas utilizadas por una familia en proceso de desgalleguización con un perfil no asentado y con unas actitudes explícitas positivas hacia la lengua minoritaria. De esta forma, detallamos las dificultades que tienen estas familias para revertir un proceso de ruptura lingüística dada la interiorización de determinadas prácticas lingüísticas. La familia escogida es Pérez-Gómez (Tabla 1); sus progenitores, Javier y Julia, aunque usan principalmente el idioma gallego en el trabajo, tienen como idioma vehicular en casa el castellano, y admiten que, aunque los niños a veces usan ciertas palabras en gallego, hablan fundamentalmente en castellano en casi todos los contextos de socialización. Javier en la entrevista afirmaba que se comprometió a hablar en gallego con su hija:

(...) E coa miña filla, teño dous nenos pequenos, a maior, me comprometín a falar en galego. Dixen, nada, pois, entre nós imos falar en galego. [En gallego, idioma original de la entrevista].

(...) con mi hija, tengo dos niños pequeños, la mayor, me comprometí a hablar en gallego. Dije, nada, pues, entre nosotros vamos a hablar en gallego. [traducción propia].

La selección de las expresiones firmes como «me comprometí a hablar en gallego» y «entre nosotros vamos a hablar en gallego» subrayan que Javier asume el papel del responsable de la gestión lingüística y aplica su agencia parental para controlar las prácticas habituales de su hija. No obstante, Julia, en su entrevista, contrasta estas afirmaciones y revela que, aunque Javier lo intenta, «se le olvida casi siempre (risas) su compromiso». Por otra parte, Julia comenta la existencia de varias tentativas fracasadas para utilizar de forma habitual el idioma gallego en casa y asocia estos resultados con el hecho de que tanto ella como su marido tienen el castellano como idioma principal. Ante esta situación, decidieron compensar este desequilibrio introduciendo el gallego a través de diferentes estrategias de alfabetización (p. ej., canciones infantiles y cuentos para dormir); 
Lo intentamos en algún momento, pero no lo conseguimos. Lo que tenemos en casa es lecturas, muchísimas lecturas en gallego, y la música infantil es prácticamente toda en gallego. Cantamos en gallego, leemos mucho en gallego, pero conversación en gallego tenemos muy poca. Y tenemos que mejorarlo. [Entrevista en castellano].

El extracto anterior no solo subraya las preocupaciones de esta pareja sobre la transmisión intergeneracional del gallego, sino también las estrategias que ellos llevan a cabo para crear un espacio favorable para la adquisición lingüística del idioma minoritario en el contorno familiar. El ambiente de alfabetización en el hogar, como bien sabemos, es un factor importante para adquirir competencia en la segunda lengua ${ }^{26}$, aunque esto solo no es suficiente para asegurar el uso habitual y/o rehabilitar la cadena de transmisión familiar de una lengua minoritaria en las sociedades bi(multi)lingües. Las prácticas lingüísticas declaradas de esta familia manifiestan cómo el exterior dominado por el castellano penetra en el espacio interior del hogar; las declaraciones de fidelidad hacia el gallego por parte de la pareja y su esperanza para promover el uso del idioma minoritario en el ámbito doméstico están afectados por los cambios de las familia al castellano, circunstancia que proviene de una ruptura de la transmisión que comenzó en la generación precedente y que con el paso del tiempo y de las generaciones se va asentando.

\subsection{Los procesos de regalleguización: evolución e influencia del hábitat}

Los perfiles sociolingüísticos caracterizados por procesos de regalleguización en Galicia son los grupos con una menor presencia de los caracterizados para este trabajo. Los procesos de regalleguización estarían íntimamente relacionados con el concepto de neofalante, entendido en el contexto gallego como aquella persona que aprendió a hablar en castellano, que tuvo este como idioma familiar y que en algún momento de su vida decide hablar solo o mayoritariamente en gallego ${ }^{27}$. El neofalante forma parte de un movimiento social conformado por personas que adoptan una práctica consciente a favor de una lengua minoritaria; a diferencia de otros grupos que tienen objetivos parecidos, en estos hablantes se produce una condición excepcional: el desplazamiento de la lengua materna por una lengua aprendida en la socialización secundaria ${ }^{28}$, con menor prestigio social y en una situación sociolingüística regresiva. Esta práctica consciente, conocida también como desplazamiento de la lengua mayoritaria ${ }^{29}$, es consecuencia tanto del fomento público del gallego como de una toma de consciencia respecto de la situación regresiva de la lengua, lo que altera el orden sociolingüístico y contribuye a la emergencia de una serie de tensiones.

Las familias que experimentan procesos de regalleguización incluyen entre sus miembros a neofalantes que transmiten la lengua minoritaria a sus descendientes. En definitiva, los perfiles de regalleguización están constituidos por aquellas familias cuyos progenitores aprendieron a hablar en castellano pero que deciden transmitir el idioma gallego a sus descendientes. Se trata de un perfil sociolingüístico familiar que aumenta lentamente con el paso del tiempo y que pasa de ser un perfil anecdótico entre los nacidos antes de mediados del siglo pasado hasta alcanzar su culmen (4\%) entre los nacidos entre 1974 y 1983 (Figura 7). 
Figura 7. Distribución por cohortes de edad de los perfiles lingüísticos regalleguizadores neohablantes: asentados, no asentados.

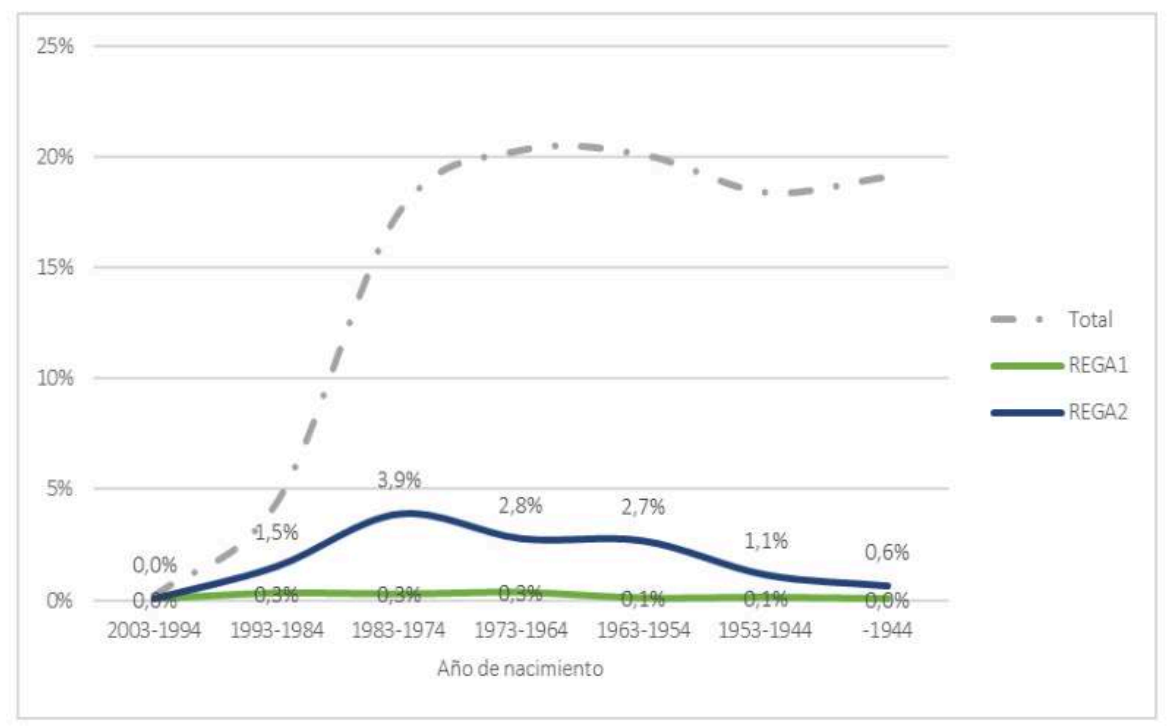

Nuestro estudio de caso relacionado con el perfil lingüístico regalleguizador es la familia Romero-Mouzo (Familia 3) de Santiago de Compostela. Los progenitores, Samuel y Raquel, son militantes de la lengua y llevan a sus dos hijas a una escuela infantil privada financiada por una asociación llamada Escolas de Ensino Galego Semente (a partir de ahora Semente) que ofrece programas de inmersión lingüística en gallego. La mayoría de los miembros de esta asociación son padres activistas que quieren que sus hijos reciban una educación en gallego. Samuel forma parte de la junta directiva de Semente y su pareja Raquel es miembro de la Asociación de Madres y Padres del centro. Durante la entrevista, Samuel cuenta la historia del centro:

Pois, cando nace Semente, nace desde a base social, desde unha asociación que detecta ese déficit absoluto do sistema que é que os: os nenos galegofalantes de pais galegofalantes cando chegan ao ensino público pois en: poucos $\mathrm{s}$ meses se castelanizan nos seus actos lingüísticos (...). En Semente, non hai ánimo de lucro, e: susténtase basicamente pola, polo traballo da militancia. [lingüística] e segue aos principios da inmersión lingüística. Semente non é un colexio só para nenos e nenas galegofalantes senón que tamén, bueno, pois houbo xente que se achegou ó proxecto e que escolarizou os seus fillos en Semente polos seus valores educativos. Que tivemos na Semente nenos castelanfalantes de familia castelanfalante que inician un proceso de adquisición de competencias en galego e que chegan a galeguizar, en certa maneira [En gallego, idioma original de la entrevista].

'Pues, cuando nace Semente, nace desde la base social, de una asociación que detecta ese déficit absoluto del sistema que los hijos gallegohablantes de los padres gallegohablantes cuando llegan a la enseñanza pública en pocos meses estos niños se convierten en castellanohablantes. (...). En Semente no hay ánimo de lucro, es básicamente respaldada por el trabajo de la militancia [lingüística] y sigue los principios de la inmersión lingüística. Semente no es solo una escuela para los niños gallegohablantes, sino que también hubo gente que se acercó al proyecto y educó a sus hijos aquí por sus valores educativos. Es decir, también tenemos en Semente, niños castellanohablantes de familias castellanohablantes que inician un proceso de adquisición de competencias en gallego y que llegan a galleguizar [sus prácticas lingüísticas], en cierto modo' [traducción propia].

El comentario anterior señala que estos progenitores activistas son conscientes de la situación sociolingüística del gallego y comenzaron a ampliar el espacio simbólico para 
el gallego a través de proyectos de dinamización social como son los programas de inmersión lingüística en gallego en educación infantil. La finalidad principal de este colectivo pro-gallego es tratar de controlar la influencia de una sociedad castellanizadora sobre los infantes gallegohablantes para que no se sientan discriminados o ridiculizados por sus compañeros castellanohablantes, lo que, según la mayoría de los entrevistados, puede acelerar el proceso de la sustitución lingüística. Durante el trabajo de campo, se realizaron varias visitas a Semente. Las notas de campo revelan que, después de las horas lectivas, el espacio escolar frecuentemente se convierte en un contexto galleguizador porque muchos miembros del colectivo progallego organizan varios eventos extracurriculares relacionados con la lengua y cultura gallega para los menores. Eso incluye juegos populares, actividades con música gallega y clases de baile tradicional. También se aprovecha esta área para organizar fiestas populares (p.ej., el Magosto ${ }^{30}$ o la visita del Apalpador ${ }^{31}$ antes de la Navidad) con los pequeños. Cabe mencionar aquí que los alumnos de otros colegios también pueden participar en estos eventos pagando una pequeña contribución. Las iniciativas descritas indican cómo este grupo promueve el uso del gallego a través de un abanico de herramientas colectivas de gestión lingüística en un contexto sumamente castellanizador.

Figura 8. Distribución por hábitat de residencia de los perfiles lingüísticos regalleguizadores: asentados, no asentados.

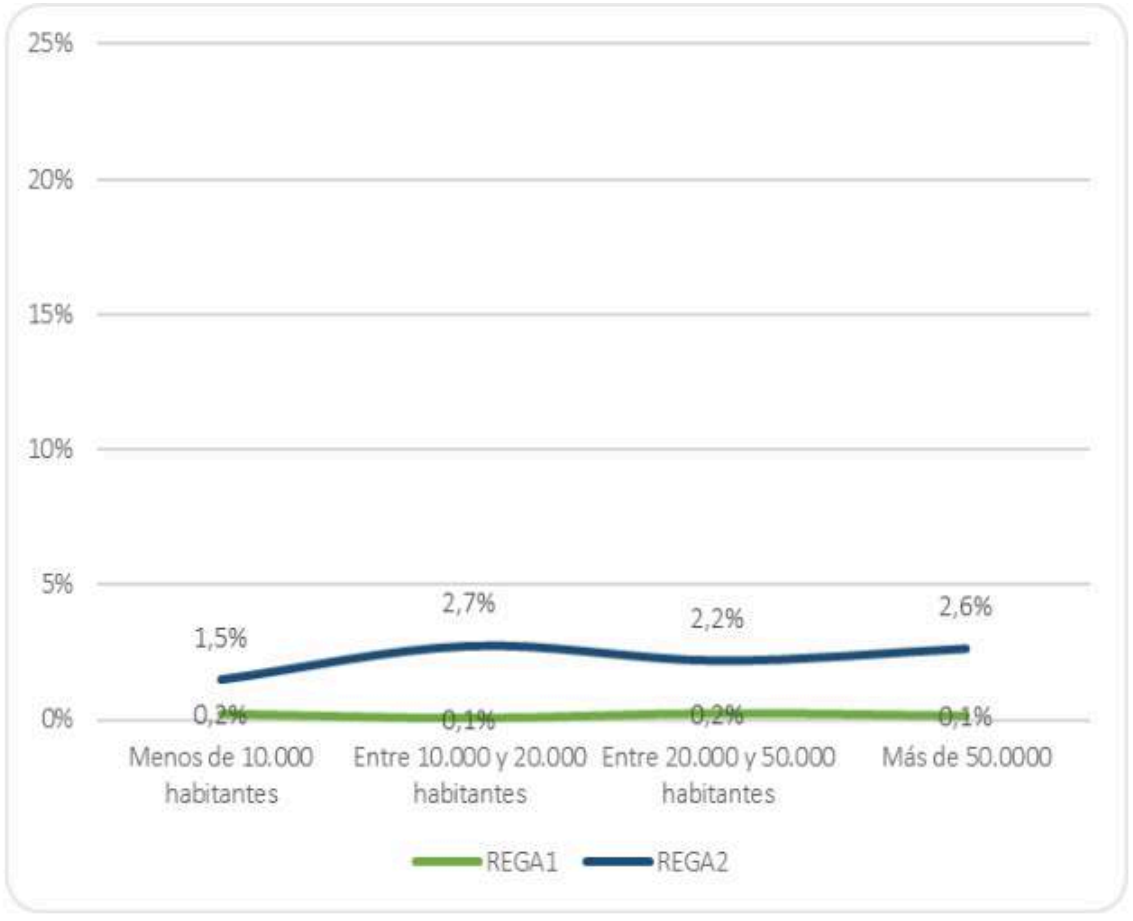

\section{Conclusiones}

41 La sociedad gallega se caracteriza por la coexistencia de dos lenguas oficiales, el gallego y el castellano. Actualmente, cada una de ellas cuenta con un número de hablantes habituales semejante, aunque la práctica totalidad de la población declara tener competencias bilingües. En este contexto sociolingüístico, al castellano se le considera 
como el idioma dominante y al gallego como una lengua minorizada, de ahí la existencia de PL públicas que buscan controlar el efecto de los procesos de sustitución lingüística. Valorando exclusivamente el número de hablantes, el gallego es una lengua con una vitalidad demográfica incuestionable, especialmente cuando se compara su situación con la de otros idiomas minoritarios con características similares. No obstante, la relación entre las lenguas cooficiales en Galicia no se puede considerar precisamente como armónica ${ }^{32}$.

Indicadores como la transmisión intergeneracional o las prácticas lingüísticas en la gente más joven caracterizan la convivencia de las dos lenguas oficiales como un proceso de sustitución en el que los hablantes del gallego dejan de usarlo, lo usan en cada vez menos ámbitos de comunicación o dejan de transmitirlo de generación en generación. Esta situación indica que las PL llevadas a cabo hasta el momento en la región, centradas especialmente en el contexto educativo y en la adquisición de competencias lingüísticas, han sido poco efectivas para frenar o reconducir estos procesos.

43 A pesar de las transformaciones que ha ido sufriendo en los últimos años y el peso ganado por otras instituciones, la familia continúa siendo la unidad social central para la adquisición y el aprendizaje de lenguas - particularmente las lenguas iniciales- y, por lo tanto, en la transmisión intergeneracional del idioma. Por lo tanto, continúa siendo un indicador fundamental para evaluar la vitalidad del gallego.

Teniendo esto como punto de partida, observamos que en la mayoría de las familias de Galicia el gallego es la lengua principal y lleva transmitiéndose desde hace generaciones (53,6\%), mientras que las familias donde el castellano predomina son más escasas (22\%).

Sin embargo, dado que las familias transmisoras del gallego se han caracterizado por residir en los contextos menos dinámicos socioeconómicamente que las transmisoras del castellano, su número ha ido reduciéndose con el paso de los años en favor de las segundas, asociadas a los ámbitos más dinámicos. En los niños y niñas, este viaje de las familias de un perfil GAL a CAST comienza con su escolarización en Infantil y Primaria, donde se exponen al gran valor social y simbólico del español. Esta exposición conduce a la transformación de sus prácticas lingüísticas, primero en estos contextos y finalmente en sus relaciones intrafamiliares. Conscientes de ello, algunas familias GAL con una visión crítica de la situación sociolingüística, buscan estrategias para convertir los espacios de socialización secundaria en contextos de inmersión lingüística, considerados seguros para que sus hijos e hijas puedan desenvolverse en gallego. A pesar de los esfuerzos, estas estrategias no tienen asegurado su éxito en contextos no favorables como los hábitats urbanos o periurbanos. En uno de los ejemplos comentados, vimos como las prácticas lingüísticas de una familia en uno de estos contextos se ven afectadas por un ambiente dominado por el castellano, convirtiendo sus esfuerzos en insuficientes para la reversión de un proceso de desgalleguización que comenzó en la generación precedente.

Igualmente, observamos que los procesos de regalleguización, aunque tienen gran trascendencia a nivel ideológico, no son significativos demográficamente, con una presencia que no alcanza el 2,5\% de las familias, habiendo llegado a ser el $4 \%$ durante los años setenta y ochenta.

Por otro lado, los resultados muestran cómo se produjo cronológicamente este proceso de sustitución lingüística en el contexto familiar y ponen el foco en las prácticas 
lingüísticas. Indican también que las familias con una ruptura de la transmisión intergeneracional del idioma gallego, producida durante la generación de los progenitores o produciéndose actualmente con sus hijos, son muy numerosas (22\%).

Estas familias en vías de desgalleguización difieren entre sí, en la manera en que las transformaciones se han producido y según si se trata de un proceso asentado o no. Los DESGA2 asentados se relacionan con migraciones internas del ámbito rural al urbano en los que la introducción del castellano en la transmisión familiar se percibía como una forma de facilitar el ascenso social en los nuevos contextos. En cambio, en los DESGA1 la introducción del castellano proviene de la socialización secundaria, permeando poco a poco en el contexto familiar hasta romper la cadena de transmisión.

En resumen, el gallego es la lengua más hablada en Galicia en la actualidad y esto es así porque las familias gallegas transmitieron su lengua propia de una generación a la siguiente durante años. Desde el siglo pasado, el número de familias que rompieron la cadena de transmisión intergeneracional hasta llegar a perder toda presencia de esta lengua ha ido aumentando, primero lentamente y con más fuerza en los últimos años. Si nada se lo impide, este proceso terminará con la completa sustitución de la lengua gallega por la castellana en el ámbito familiar, un espacio que ha sido decisivo para su llegada al siglo XXI con una vitalidad demográfica considerable. En términos generales, estos procesos de desgalleguización tienen un impacto muy superior a los de regalleguización, aunque estos tienen una gran relevancia, dado que se producen en un contexto claramente desfavorable: el desplazamiento de la lengua materna por un idioma adquirido en la socialización secundaria, con un menor prestigio social y en una situación regresiva.

\section{BIBLIOGRAFÍA}

Louis-Jean CALVET, La guerre des langues et les politiques linguistiques, Paris, Payot, 1987.

Xiao Lan CURDT-CHRISTIANSEN, «Visible and invisible language planning: Ideological factors in the family language policy of Chinese immigrant families in Quebec», Language Policy, 8 (2009), p. 351-375.

Almudena COTÁN FERNÁNDEZ, «El método etnográfico como construcción del conocimiento, un análisis descriptivo sobre su uso y conceptualización en ciencias sociales», Márgenes: Revista de Educación de la Universidad de Málaga, 1(1) (2020), p.83-103.

INSTITUTO GALEGO DE ESTATística (2018), «Enquisa estrutural a fogares. Coñecemento e uso do galego» [en línea], Galicia [consultado el 11-09-2020] <URL: https://www.ige.eu/web/ mostrar_actividade_estatistica.jsp?idioma $=$ gl\&codigo $=0206004 />$.

Manuel GONZÁLEZ GONZÁLEZ (dir.), Dicionario da Real Academia Galega, A Coruña: Real Academia Galega, [Consultado: <15/04/2021>] <https://academia.gal/dicionario>.

Einar HAUGEN, The Ecology of Language. Essays by Einar Haugen, Stanford, Stanford University Press, 1972. 
Kendall A. KING, «Language policy, multilingual encounters, and transnational families», Journal of Multilingual and Multicultural Development, 37(7) (2016), p.726-733.

Elizabeth LANZA, «Multilingualism and the family», Peter Auer y Li Wei (eds.), Handbook of Multilingualism and Multilingual Communication, Berlin, Mouton de Gruyter (2007), p. 45-66.

Xaquín LOREDO, «O retroceso da transmisión lingüística en Galicia», Grial: Revista Galega de Cultura, 216 (2017), p. 30-37.

Xaquín LOREDO y Henrique MONTEAGUDO (2017), «La transmisión intergeneracional del gallego. Comparación con el catalán», Treballs de Sociolingüística Catalana, 27 (2017), p. 99-116.

Henrique MONTEAGUDO, «Política lingüística en Galicia: de la normalización sin conflicto al conflicto desnormalizador», Javier Giralt Latorre y Francho Nagore Laín (eds.), La normalización social de las lenguas minoritarias. Experiencias y procedimientos para la salvaguarda de un patrimonio inmaterial, Zaragoza. Prensas de la Universidad de Zaragoza (2019), p. 17-55.

Henrique MONTEAGUDO, Xaquín LOREDO y Martín VÁZQUEZ, Lingua e sociedade: a evolución sociolingüística 1992-2016, A Coruña, Real Academia Galega, 2018, p.137 [consultado el 01-11-2020] <URL: http://publicacions.academia.gal/index.php/rag/catalog/book/327 >.

Anik NANDI, Language policies on the ground: Parental language management in urban Galician homes, Tesis Doctoral, Edinburgh, Heriot-Watt University, 2017.

Anik NANDI, «Language Policies and Linguistic Culture in Galicia», Labor Histórico, 3(2) (2017), p. 28-45. [consultado el 01-09-2020] <URL: https://doi.org/10.24206/lh.v3i2.17124 >.

Anik NANDI, « Parents as stakeholders: Language management in urban Galician homes», Multilingua: Journal of Cross-Cultural and Interlanguage Communication, 37(2) (2018), 201-223. Anik NANDI, «Política lingüística familiar. O papel dos proxenitores pro-galego na transmisión interxeracional», Estudos da Lingüística Galega, 11 (2019), 77-101.

Anik NANDI, «Micropolíticas lingüísticas familiares de resistencia. Estrategias parentales para la transmisión intergeneracional del gallego», Revista Española de Lingüística Aplicada/Spanish Journal of Applied Linguistics, en prensa.

Bernadette O'ROURKE y Fernando RAMALLO, «Neofalantes as an active minority: Understanding language practices and motivations for change amongst new speakers of Galician», International Journal of the Sociology of Language, 231 (2015), p. 147-165.

Fernando RAMALLO, «El gallego en la familia entre la producción y la reproducción», Caplletra: Revista Internacional de Filología, 53 (2012), p. 167-191.

Fernando RAMALlo, «Neofalantismo», Consello da Cultura Galega (ed.), Contacto de linguas, hibridade, cambio: contextos, procesos e consecuencias, Santiago de Compostela, Consello da Cultura, 2013, p. 245-258.

Manuel REGUEIRO TENREIRO, Modelo harmónico de relación lingüística. Estudio en Galicia, 3 Catorce Euro Ediciones, 1999.

Thomas K. RICENTO y Nancy H. HORNBERGUER, «Unpeeling the Onion: Language Planning and Policy and the ELT Profession», TESOL Quarterly, 30 (1996), p. 401-427.

Johny SALDAÑA, The Coding Manual for Qualitative Researchers (3 ed.), Arizona, Arizona State University, 2015.

Bernard SPOLSKY, Language Policy, Cambridge, Cambridge University Press, 2004. 
Xaime SUBIELA, «O idioma galego, alarmas e esperanzas», Tempos Novos. Anuario 2010 (2010), p. 247-276.

UNESCO (2003), «Language Vitality and Endangerment» [on-line], Documento adoptado por la Reunión Internacional de Expertos sobre el programa de la UNESCO, Salvaguardia de las lenguas en Peligro, p. 2, París [consultado el 01-09-2020] <URL: http://www.unesco.org/new/fileadmin/ MULTIMEDIA/HQ/CLT/pdf/Language_vitality_and_endangerment_EN.pdf>.

\section{NOTAS}

1. UNESCO (2003), «Language Vitality and Endangerment» [on-line], Documento adoptado por la Reunión Internacional de Expertos sobre el programa de la UNESCO, Salvaguardia de las lenguas en Peligro, p. 2, París [consultado el 01-09-2020] <URL:http://www.unesco.org/new/fileadmin/ MULTIMEDIA/HQ/CLT/pdf/Language_vitality_and_endangerment_EN.pdf/>.

2. Henrique MONTEAGUDO, «Política lingüística en Galicia: de la normalización sin conflicto al conflicto desnormalizador», Javier Giralt Latorre y Francho Nagore Laín (eds.), La normalización social de las lenguas minoritarias. Experiencias y procedimientos para la salvaguarda de un patrimonio inmaterial, Zaragoza. Prensas de la Universidad de Zaragoza (2019), p. 17-55; Anik NANDI, «Language Policies and Linguistic Culture in Galicia», Labor Histórico, 3(2) (2017), p. 28-45. [consultado el 01-09-2020] <URL: https://doi.org/10.24206/lh.v3i2.17124 >.

3. INSTITUTO GALEGO DE ESTATÍSTICA (2018), «Enquisa estrutural a fogares. Coñecemento e uso do galego» [en línea], Galicia [consultado el 11-09-2020] <URL: https://www.ige.eu/web/ mostrar_actividade_estatistica.jsp?idioma=gl\&codigo=0206004/>.

4. Henrique MONTEAGUDO, Xaquín LOREDO y Martín VÁZQUEZ, Lingua e sociedade: a evolución sociolingüística 1992-2016, A Coruña, Real Academia Galega, 2018, p.137 [consultado el 01-11-2020] <URL: http://publicacions.academia.gal/index.php/rag/catalog/book/327 >.

5. Xaime SUBIELA, «O idioma galego, alarmas e esperanzas», Tempos Novos. Anuario 2010 (2010), p. 247-276.

6. Xaquín LOREDO, «O retroceso da transmisión lingüística en Galicia», Grial: Revista Galega de Cultura, 216 (2017), p. 30-37.

7. Elizabeth LANZA, «Multilingualism and the family», Peter Auer y Li Wei (eds.), Handbook of Multilingualism and Multilingual Communication, Berlin, Mouton de Gruyter (2007), p. 45-66.

8. Anik NANDI, «Política lingüística familiar. O papel dos proxenitores pro-galego na transmisión interxeracional», Estudos da Lingüística Galega, 11 (2019), 77-101.

9. Fernando RAMALLO, «El gallego en la familia entre la producción y la reproducción», Caplletra: Revista Internacional de Filología, 53 (2012), p. 167-191.

10. Louis-Jean CALVET, La guerre des langues et les politiques linguistiques, Paris, Payot, 1987.

11. Xiao Lan CURDT-CHRISTIANSEN, «Visible and invisible language planning: Ideological factors in the family language policy of Chinese immigrant families in Quebec», Language Policy, 8 (2009), p. 351-375.

12. Kendall A. KING, «Language policy, multilingual encounters, and transnational families», Journal of Multilingual and Multicultural Development, 37(7) (2016), p.726-733.

13. Bernard SPOLSKY, Language Policy, Cambridge, Cambridge University Press, 2004.

14. Einar HAUGEN, The Ecology of Language. Essays by Einar Haugen, Stanford, Stanford University Press, 1972.

15. Anik NANDI, "Parents as stakeholders: Language management in urban Galician homes», Multilingua: Journal of Cross-Cultural and Interlanguage Communication, 37(2) (2018), 201-223. 
16. Anik NANDI, «Micropolíticas lingüísticas familiares de resistencia. Estrategias parentales para la transmisión intergeneracional del gallego», Revista Española de Lingüística Aplicada/Spanish Journal of Applied Linguistics, en prensa.

17. InSTITUTO GALEGO DE ESTATísTica (2018), op. cit.

18. Thomas K. RICENTO y Nancy H. HORNBERGUER, «Unpeeling the Onion: Language Planning and Policy and the ELT Profession», TESOL Quarterly, 30 (1996), p. 401-427.

19. Almudena COTÁN FERNÁNDEZ, «El método etnográfico como construcción del conocimiento, un análisis descriptivo sobre su uso y conceptualización en ciencias sociales», Márgenes: Revista de Educación de la Universidad de Málaga, 1(1) (2020), p.83-103.

20. Cabe mencionar que los datos presentados en este artículo derivan de un corpus más amplio de una investigación doctoral (2012-16), que se basa principalmente en dieciocho entrevistas semiestructuradas, realizadas individualmente, a progenitores con diversas situaciones profesionales en Santiago de Compostela, Bertamiráns, Ferrol y Esteiro-Muros y dos grupos de discusión con cuatro parejas tanto en Vigo como en Santiago de Compostela, (Cf. Anik NANDI, Language policies on the ground: Parental language management in urban Galician homes, Tesis Doctoral, Edinburgh, Heriot-Watt University, 2017).

21. Johny SALDAÑA, The Coding Manual for Qualitative Researchers (3 ed.), Arizona, Arizona State University, 2015.

22. Xaquín LOREDO y Henrique MONTEAGUDO (2017), «La transmisión intergeneracional del gallego. Comparación con el catalán», Treballs de Sociolingüística Catalana, 27 (2017), p. 99-116.

23. Henrique MONTEAGUDO, Xaquín LOREDO y Martín VÁzQUEZ, op. cit.

24. Cabe indicar que entre los nacidos entre 1994 y 2003 los porcentajes de desgalleguización descienden drásticamente $(3,1 \%)$, pero estos datos no los podemos considerar tan fiables como el resto de las cohortes de edad dada la escasa presencia de familias con hijos en este tramo de edad.

25. Entidad de población más pequeña que una ciudad y más grande que una aldea, que en Galicia suele tener núcleo urbano y ser centro económico y administrativo de un municipio o de una comarca, Manuel GONZÁLEZ GONZÁLEZ (dir.), Dicionario da Real Academia Galega, A Coruña: Real Academia Galega, [Consultado: <15/04/2021>] <URL: https://academia.gal/dicionario>, (traducción propia).

26. Xiao Lan CURDT-CHRISTIANSEN, «Visible and invisible language planning: Ideological factors in the family language policy of Chinese immigrant families in Quebec», Language Policy, 8(4), (2009), P. 351-375.

27. Fernando RAMALLo, op. cit.

28. Fernando RAmallo, «Neofalantismo», Consello da Cultura Galega (ed.), Contacto de linguas, hibridade, cambio: contextos, procesos e consecuencias, Santiago de Compostela, Consello da Cultura, 2013, p. 25

29. Bernadette O'ROURKE y Fernando RAMALLO, «Neofalantes as an active minority: Understanding language practices and motivations for change amongst new speakers of Galician», International Journal of the Sociology of Language, 231 (2015), p. 147-165.

30. Tradicionalmente, el magosto era una fiesta en torno al fuego y a las castañas asadas con la que los gallegos honraban las cosechas en los principios del mes de noviembre.

31. Una figura mítica de Galicia que trae regalos de Navidad para los niños.

32. El modelo armónico de convivencia entre lenguas para Galicia, el denominado bilingüismo armónico, fue desarrollado por Manuel Regueiro Tenreiro ( $C f$. Manuel REGUEIRO TENREIRo, Modelo harmónico de relación lingüística. Estudio en Galicia, 3 Catorce Euro Ediciones, 1999). 


\section{RESÚMENES}

Aunque actualmente la lengua gallega disfruta de una alta vitalidad demográfica, factores como la disminución de gallegohablantes (especialmente entre la población más joven residente en ámbitos urbanos/periurbanos) y la erosión de los procesos de transmisión lingüística intergeneracional plantean dudas sobre su futuro. En esta situación consideramos necesario estudiar el papel de los diferentes agentes sociales implicados en los procesos de mantenimiento y recuperación de la lengua, en especial las familias, con la finalidad de reconducir las políticas lingüísticas, poco efectivas, que hasta el momento se han llevado a cabo en Galicia. El objetivo de este trabajo es presentar una tipología de perfiles sociolingüísticos familiares, estudiar su evolución temporal y distribución espacial para, posteriormente, analizar las distintas estrategias lingüísticas de cada perfil.

Bien qu'actuellement la langue galicienne bénéficie d'une grande vitalité démographique, des facteurs comme la diminution du nombre de locuteurs en galicien (notamment parmi la population la plus jeune résidant dans les populations urbaines / périurbaines) et l'érosion des processus de transmission linguistique intergénérationnelle soulèvent des doutes sur son devenir. Dans cette situation, il est nécessaire d'étudier le rôle des différents agents sociaux impliqués dans les processus de maintien et de réappropriation de la langue, spécialement les familles. L'objectif de ce travail est de présenter une typologie des profils sociolinguistiques familiaux, d'étudier leur évolution dans le temps ainsi que leur répartition spatiale pour, enfin, analyser les diverses stratégies linguistiques de chaque profil et les politiques, peu efficaces, qui ont été mises en œuvre en Galice jusqu'à présent.

Although the Galician language currently enjoys a high demographic vitality, factors such as the decline in Galician speakers (especially among the younger population living in urban/semiurban domains) and the interruption in the processes of intergenerational transmission raise doubts about the future of the minority language. In this situation, it is relevant to study the role of the different social agents involved in the language maintenance and revitalisation discourses, especially the role of family members in this process to redirect the ineffective language policies that are being implemented in Galicia since the beginning of the Autonomy. The purpose of this article is to offer a typology of different family sociolinguistic profiles while studying their temporal evolution and spatial distribution. The intention is also to analyse the different linguistic strategies these families employ to maintain or revitalise Galician.

\section{ÍNDICE}

Palabras claves: Sustitución lingüística, transmisión intergeneracional, revitalización, gallego

Keywords: Language shift, intergenerational transmission, revitalization, Galician, sociolinguistics

Mots-clés: Substitution linguistique, transmission intergénérationnelle, revitalisation, galicien

\section{AUTORES}

\section{HENRIQUE MONTEAGUDO}

Instituto da Lingua Galega. Universidade de Santiago de Compostela 


\section{ANIK NANDI}

Leiden University Centre for Linguistics

XAQUÍN LOREDO

Seminario de Sociolingüística da Real Academia Galega 